https://doi.org/10.48009/4_iis_2019_35-44

Issues in Information Systems

Volume 20, Issue 4, pp. 35-44, 2019

\title{
ANOTHER LOOK AT TEXTBOOK USAGE BY COLLEGE STUDENTS
}

\author{
Xue Bai, Virginia State University, xbai@vsu.edu \\ Ade Ola, Virginia State University, aola@vsu.edu \\ Ephrem Eyob, Virginia State University, eeyob@vsu.edu \\ Serena Reese, Virginia State University, sreese@vsu.edu \\ Soma Akkaladevi, Virginia State University, sakaladevi@vsu.edu \\ Daysha Downing, Virginia State University, ddowning@vsu.edu
}

\begin{abstract}
The textbook is one of the most important sources of knowledge. It remains the definitive source of content for the knowledge and skills that students should acquire within a prescribed curriculum. However, research has been shown that there is a decline in the rate of reading of texts among college students. There are also conflicting research results on whether textbook reading in university-level courses is correlated with improvements in student grades. The conflicting results raise many questions about the role of the textbook in tertiary education. In an effort to answer these questions, we conducted a preliminary survey on textbook usage in several undergraduate and graduate courses across various disciplines. The purpose of this study is: 1) to examine the factors that motivate students to use required textbooks;2) determine their preferred textbook format and 3) investigate how students learn and prepare to meet course requirements. The results show that a majority of students used online resources instead of assigned reading materials. When textbook reading is not directly tied to assessments, students often choose to study other resources they deem to be more beneficial. The results of this study and the conflicting results from previous research on the use and efficacy of textbooks appear to suggest that the textbook as a learning instrument needs to change to support "How People Learn."
\end{abstract}

Keywords: textbook usage, online resources, e-books, learning habits, learning materials.

\section{INTRODUCTION}

The textbook has always been a central vehicle for instruction and learning, particularly in formal education settings. Traditionally, textbooks have been used to guide instruction in courses within a curriculum, as they serve as the singular source of material and content in a particular branch of study. Even with the availability of other learning materials such as videos, simulators, interactive games, and tutoring systems, the textbook remains the definitive source of content for the knowledge and skills that students should acquire within the prescribed curriculum. Instructors continue to promote textbook reading as a way for students to improve their academic performance and expect students to complete assigned readings. In addition, many of the study strategies suggested by university academic success centers relate to textbook reading.

The general assumption is that textbook reading enhances student learning notwithstanding, it has been shown that there is a decline in the rate of reading of texts by students (Burchfield \& Sappington, 2000). Additionally, a significant proportion of college students do not read course texts either in preparation for class sessions or examinations (Aagaard \& Skidmore, 2004; Clump, Bauer, \& Bradley, 2004; Sikorski, Rich, Saville, Buskist, Drogan, \& Davis 2002). Sikorski et al. (2002) reported that students spend less than three hours per week reading their textbooks. The research on student-reported reading compliance in both introductory and advanced courses is low, ranging from about 20\% to 70\% (Burchfield \& Sappington 2000; Cummings, French, \& Cooney 2002; Sikorski et al., 2002; Marchant, 2002; Clump, Bauer, \& Bradley 2004; Podolefsky \& Finkelstein 2006; Starcher \& Proffitt 2011; Berry, Cook, Hill, \& Stevens. 2011; Hoeft 2012; and French, Taverna, Neumann, Kushnir, Harlow, Harrison, \& Serbanescu., 2015). Research (Aagaard \& Skidmore, 2009; Fischer, Hilton, Robinson, \& Wiley, 2015) also shows that students have developed a different perspective from the expectations of their instructors with regard to the purpose, necessity, and use of textbooks. 


\section{Issues in Information Systems}

Volume 20, Issue 4, pp. 35-44, 2019

Perhaps even more alarming, there are conflicting results about whether textbook reading in university-level courses is correlated with improvements in student grades in the few instances where it has been studied. Podolefsky and Finkelstein (2006) conducted a study on textbook use in four introductory college physics courses; their survey results indicated that while over $97 \%$ of students bought the required textbook, less than $41 \%$ reported that they read it regularly. Their research found that there was little (or no) correlation between reading habits and course grade. Further analysis of how and why students read indicated little or no variation in the perceived value of the textbook for course components tightly coupled to grades. Similar results were found across conceptual-, algebra-, and calculus-based courses with different instructors and textbooks (Podolefsky \& Finkelstein, 2006). On the other hand, Sappington, Kinsey, and Munsayac (2002) found that performance of upper-year psychology students on an initial surprise reading quiz, which largely measured reading compliance rather than comprehension, predicted future exam scores. Those students who passed the quiz averaged $84 \%$ on the exam, while those who failed the quiz averaged $68 \%$ on the exam. In a study focused mainly on textbook usage, Landrum, Gurung, and Spann (2012) reported a significant positive correlation between "percentage of reading completed" and higher quiz/final grades in a general psychology course.

The conflicting results described above raise many questions about the role of the textbook in tertiary education. Given the conflicting results on the use and efficacy of textbooks, is there is any point in even assigning one? If students are reluctant to use textbook, how do they prepare for tests or gain the fundamental knowledge to meet the course requirements? Alternatively, if instructors believe that textbook reading or any other format of reading materials promotes a deeper understanding of the course material and life-long learning skills, are there strategies that instructors should implement in their courses to promote textbook reading? In an effort to answer these questions, we conducted a preliminary survey on textbook usage in several undergraduate and graduate courses across various disciplines. The objective of the study is: 1) to examine the factors that motivate students to use required textbooks, 2) determine their preferred textbook format and 3) investigate how students learn and prepare to meet course requirements.

\section{METHODS}

The study participants enrolled in 15 undergraduate and graduate courses across various disciplines. Participation was entirely voluntary and no course marks were awarded for completing the survey. This study employed a convenient cluster sample of 283 students from 15 classes in Fall 2018 and Spring 2019 semesters at a regional university in the South-Central region (see Table 1).

Table 1. Student Distributions Based on the Disciplines

\begin{tabular}{lcc}
\hline Courses & $\mathrm{n}$ & $\%$ \\
\hline General Education Courses & 174 & $61 \%$ \\
Computer Science* & 88 & $31 \%$ \\
Statistics & 21 & $7 \%$ \\
\hline
\end{tabular}

*Including Computer Programming, Networking and Web Design

About $38 \%$ of the students were in science and technology courses and $62 \%$ were in health and physical education courses. The general education courses are elective courses with students from all disciplines across the campus colleges. The distribution of the students by classification is shown in Table 2 . 


\section{Issues in Information Systems}

Volume 20, Issue 4, pp. 35-44, 2019

Table 2. Student Distribution According to Classification

\begin{tabular}{lcc}
\hline Classification & $\mathrm{n}$ & $\%$ \\
\hline Freshman & 66 & $23 \%$ \\
Sophomore & 77 & $27 \%$ \\
Junior & 64 & $23 \%$ \\
Senior & 56 & $20 \%$ \\
Graduate & 18 & $6 \%$ \\
Others & 2 & $1 \%$ \\
\hline
\end{tabular}

Participants were administered a ten-item researcher-designed survey (see Appendix A) that included 8 items regarding the use of course textbooks, required reading materials, and their preferences of reading materials and resources. Students were provided a free-response question that allowed them to give reasons of their preference of textbook format or choice of other learning resources.

Frequency analyses were performed on every item for descriptive purposes and cross-tabulations were created of every item with use of the textbook. The cross-tabulations were visually inspected and chi-square analyses were run on selected comparisons. Chi-square tests with p-values of less than or equal to 0.05 were considered significant. As a follow-up discussion, we analyzed students' responses to the free-response questions on their preference of textbook format. Based on the data, a fishbone diagram was developed to categorize the potential causes that might affect the use of the textbook.

\section{RESULTS}

The majority of students (64\%) reported that they seldom used or never used textbooks (168 out of 262, the students in the N/A category were not included in the calculation). In order to investigate whether the number of years in college impacted the use of the textbook, data were further broken down into classifications to see if there were any patterns. As shown in Table 3, the use of the textbook seemed to decrease over the number of years in college: About $70 \%$ of freshmen and sophomores seldom or never used textbook; the percentage dropped down to $66 \%$ in the junior year and $48 \%$ for seniors and graduate students.

Table 3 Use of Textbook versus Classifications

\begin{tabular}{lcccccc}
\hline Classification & Never used & Seldom use & $1-2$ hours & $2-3$ hours & More than 4 hours & N/A \\
\hline Freshman & $28(44 \%)^{*}$ & $16(25 \%)$ & $8(13 \%)$ & $4(6 \%)$ & $8(13 \%)$ & 2 \\
Sophomore & $39(51 \%)$ & $18(23 \%)$ & $14(18 \%)$ & $1(1 \%)$ & $5(6 \%)$ & 0 \\
Junior & $16(31 \%)$ & $18(35 \%)$ & $6(12 \%)$ & $7(13 \%)$ & $5(10 \%)$ & 11 \\
Senior/Graduate & $13(19 \%)$ & $20(29 \%)$ & $23(33 \%)$ & $6(9 \%)$ & $7(10 \%)$ & 5 \\
\hline
\end{tabular}

*The number of students in N/A category was not included in calculating percentage.

Figure 1 shows that most students chose not to get the textbook if it was not free. As shown in this figure, only $42 \%$ students (120 out of 283) responded that they intended to buy the textbook even if it was not free. In order to further investigate whether buying textbook motivated the use of the textbook, we analyzed how often students used the textbook with respect to the buying / not buying response; and the summary of the data is presented in Table 3. 


\section{Issues in Information Systems}

Volume 20, Issue 4, pp. 35-44, 2019

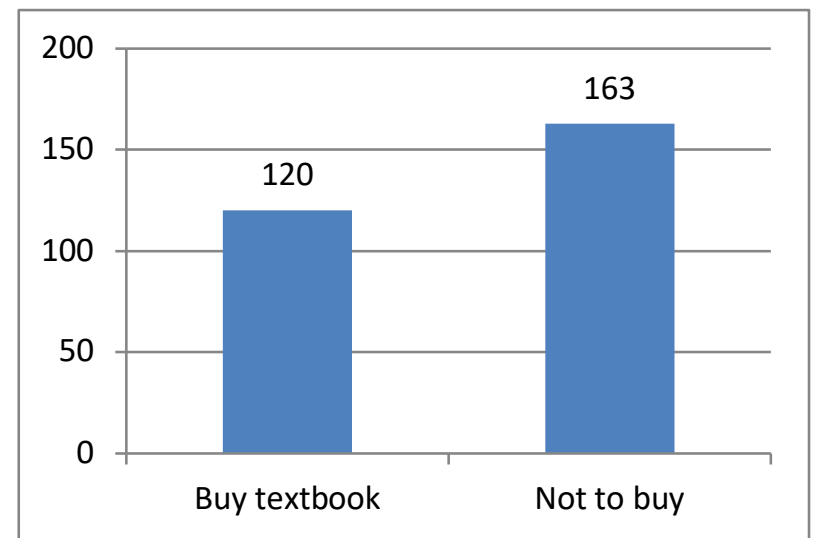

Figure 1. Intend to obtain textbook if it is not free

Table 3. Comparison of the use of textbook between two groups: buy versus not buy the textbook

\begin{tabular}{lcc}
\hline Use of Textbook & $\mathrm{N}$ (buy/not to buy) & $\%$ \\
\hline Never used textbook & $1 / 20$ & $1 \% / 14 \%$ \\
Seldom use textbook & $49 / 49$ & $42 \% / 35 \%$ \\
$1-2$ hours & $34 / 38$ & $29 \% / 27 \%$ \\
$3-4$ hours & $26 / 25$ & $22 \% / 18 \%$ \\
More than 4 hours & $8 / 9$ & $7 \% / 6 \%$ \\
\hline
\end{tabular}

As shown in Table 3, in both groups, about $72 \%$ of students spent less than two hours reading the textbook. In responding to Item 2: Is the textbook required for this course? 166 students responded yes and 115 responded no. Responses to buying or not buying the textbook were based on perception of the student because digital textbooks or various course materials were provided for free for all the courses in this survey. However, the data was still useful since their perception of buying the textbook seemed not to contribute to the use of the textbook.

Tables 4 and 5 show the use of textbook when it is required or not required (used as a reference). When a textbook was required for a course, about $66 \%$ students spent less than 2 hours reading the textbook versus $71 \%$ when the textbook was not required. More students spent more time on textbook when it was required: $57 \%$ students spent $1-4$ hours in reading the textbook when it was required and only $25 \%$ students if not required. However, the total time spent was far less than that reported in previous studies. Huang, S., Capps, M., Blacklock, J., \& Garza, M. (2014), Sheorey and Mokhtari (1994), and Mokhtari, K., Reichard, C. A., \& Gardner, A. (2009) reported averages of 7.7, 9.7, and 10.9 hours respectively.

Table 4. Student use of textbook if it is required

\begin{tabular}{lcc}
\hline Use of Textbook & $\mathrm{n}$ & $\%$ \\
\hline Never used textbook & 3 & $2 \%$ \\
Seldom use textbook & 53 & $32 \%$ \\
$1-2$ hours & 53 & $32 \%$ \\
$3-4$ hours & 41 & $25 \%$ \\
More than 4 hours & 15 & $9 \%$ \\
\hline
\end{tabular}


Table 5. Student use of textbook if it is not required (for reference)

\begin{tabular}{lcc}
\hline Use of Textbook & $\mathrm{n}$ & $\%$ \\
\hline Never used textbook & 18 & $16 \%$ \\
Seldom use textbook & 44 & $39 \%$ \\
$1-2$ hours & 18 & $16 \%$ \\
$3-4$ hours & 10 & $9 \%$ \\
More than 4 hours & 2 & $2 \%$ \\
NA-no textbook & 21 & $19 \%$ \\
\hline
\end{tabular}

Tables 6 and 7 show textbook preference and use of each type of textbook. Table 6 shows students' preference of textbook for the course if given an option. Most students prefer digital materials (e-book and online resources); it counts for $67 \%$. Table 7 illustrates the use of textbook and textbook type. As shown in the table, students spent more time on reading e-books. If we combine the three categories: 1-2 hours, 2-3 hours and more than 4 hours, $70 \%$ of students read e-book and $49 \%$ of students used a hard copy textbook. The results show that students spent more time on the e-book which is consistent with their textbook preference shown in table 6.

Table 6. Textbook Format Preference

\begin{tabular}{lcc}
\hline Textbook Type & $\mathrm{n}$ & $\%$ \\
\hline Hard copy & 51 & $18 \%$ \\
e-book & 105 & $37 \%$ \\
online resources compiled by instructor & 84 & $30 \%$ \\
Instructor hand-out & 29 & $10 \%$ \\
Others & 13 & $5 \%$ \\
\hline
\end{tabular}

Table 7. The use of textbook and textbook type

\begin{tabular}{lccccc}
\hline Textbook Type & Seldom use & $\begin{array}{l}1-2 \\
\text { hours }\end{array}$ & $\begin{array}{l}2-3 \\
\text { hours }\end{array}$ & More than 4 hours & Never used \\
\hline $\begin{array}{l}\text { Hard copy } \\
\text { e-book }\end{array}$ & $36(51 \%)$ & $12(17 \%)$ & $18(25 \%)$ & $5(7 \%)$ & $0(0 \%)$ \\
Hard copy but not required & $26(27 \%)$ & $40(42 \%)$ & $19(20 \%)$ & $8(8 \%)$ & $3(3 \%)$ \\
$\begin{array}{l}\text { e-book or free online } \\
\text { materials but not required }\end{array}$ & $11(69 \%)$ & $1(6 \%)$ & $3(19 \%)$ & $0(0 \%)$ & $1(6 \%)$ \\
Handouts by instructor & $20(34 \%)$ & $16(28 \%)$ & $7(12 \%)$ & $4(7 \%)$ & $11(19 \%)$ \\
\hline
\end{tabular}

Table 8 summarizes the use of the textbook when the textbook was required. It shows that if instructors assigned homework questions directly from the course textbook, students were motivated to spend more time using it. This is related to the perceived benefit of reading the textbook or assigned reading material because students believe the learning materials would be directly related to the assessment items and would boost their grades. If no homework questions were from the textbook, about $63 \%$ of students did not or seldom used the textbook.

Table 8. Use of Textbook if homework questions directly from textbook if textbook is required

\begin{tabular}{cccccc}
\hline Homework from textbook & Seldom use & $1-2$ hours & $2-3$ hours & More than 4 hours & Never used \\
\hline Yes & $26(21 \%)$ & $47(39 \%)$ & $31(26 \%)$ & $15(12 \%)$ & $2(2 \%)$ \\
No & $24(62 \%)$ & $6(15 \%)$ & $8(21 \%)$ & $0(0 \%)$ & $1(3 \%)$ \\
\hline
\end{tabular}




\section{Issues in Information Systems}

Volume 20, Issue 4, pp. 35-44, 2019

From the data, students appeared to spend far less time on textbooks than expected. However, the data did not show that there is a significant impact of less reading on the performance on tests; it appears students rely more on online resources. Table 9 compared the use of online resources if the textbook was required versus not required. The Chisquare test result shows that requiring the textbook did not make a significant difference on the use of online resources $(p=0.539)$. Regardless of whether the textbook was required or not, more than $80 \%$ of students used online resources during these classes. This may partially explain why students spent less time on reading the required textbook.

Table 9. Use Online Resources

\begin{tabular}{ccc}
\hline & Use Online Resources & \multicolumn{2}{c}{$\begin{array}{c}\text { Did not use Online } \\
\text { Resource }\end{array}$} \\
\hline Textbook was required & 134 & 32 \\
No & 97 & 19 \\
\hline
\end{tabular}

Chi-square test: $\mathrm{p}=0.539$

In order to investigate whether the number of years in college impacted the use of online resources, the data were further broken down by student classification. As shown in Table 11, students in the sophomore year used online resources the most, and surprisingly, senior and graduate students did not use online resources as much as juniors and sophomores. The Chi-square test results show significant differences on the use of online resources among the different classifications.

Table 11. Use of online resources over number of years in college

\begin{tabular}{lcc}
\hline Classification & Use Online Resources & $\begin{array}{c}\text { Did not use Online } \\
\text { Resource }\end{array}$ \\
\hline Freshman & $51(77 \%)$ & $15(23 \%)$ \\
Sophomore & $71(92 \%)$ & $6(8 \%)$ \\
Junior & $55(87 \%)$ & $8(13 \%)$ \\
Senior/Graduate & $54(73 \%)$ & $20(27 \%)$ \\
\hline
\end{tabular}

Chi-square test: $\mathrm{p}=0.0076$

To further investigate why students read the textbook less over the years, we analyzed students' responses to the free-response questions on their preference of the textbook format. In the free response question, participants were asked to give reasons of their preference on the textbook format and list what are the most important features a "good textbook" should have and most important reasons why they DO NOT/ SELDOM read textbook, or features they do not like. We extracted the terms they used in their responses and frequencies of each term were summarized. Based on the data, a fishbone diagram was developed to categorize the potential causes that might affect the use of the textbook. 


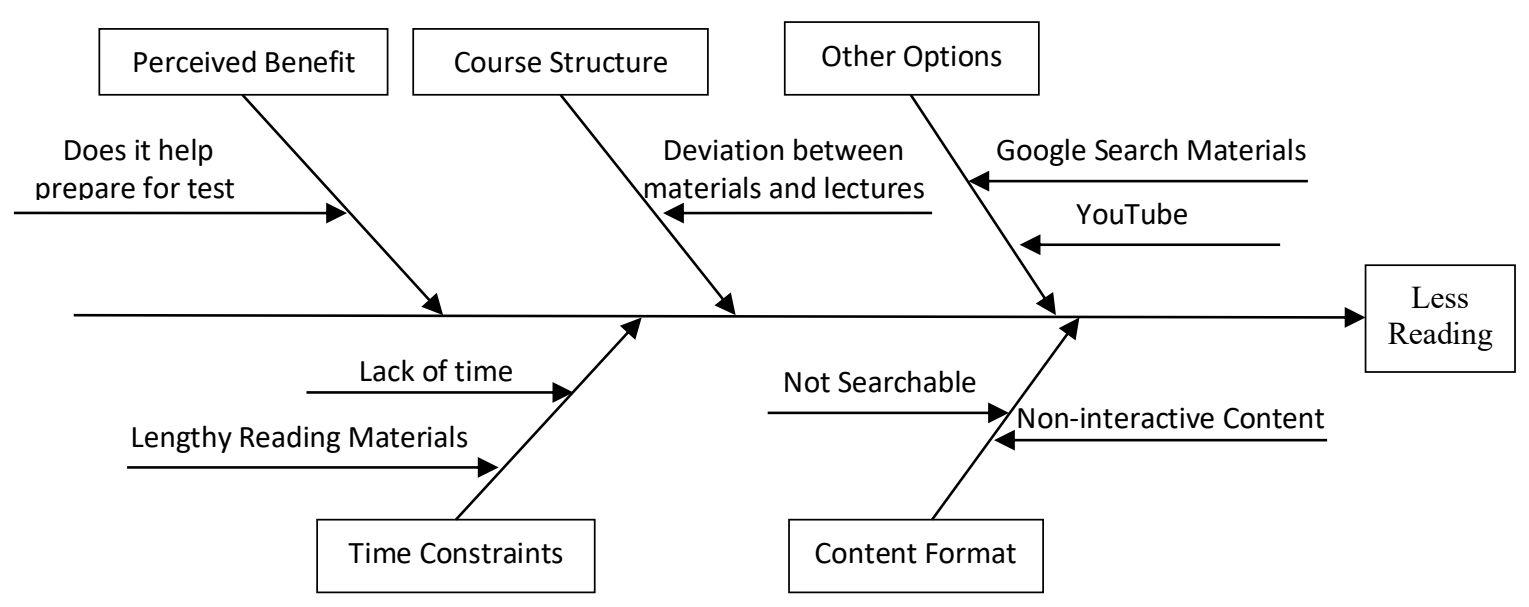

Figure 2. Less Reading Textbook Causes and Effect Fishbone Diagram

Among all the causes listed in Figure 2, more than $65 \%$ of the students responded that they preferred just researching specific topics on Google or YouTube and learning the material for the topics when needed. About 50\% of the students listed "not searchable and non-interactive content" as the reason for not reading the assigned or referenced textbook; instead they turned to online resources for the specific topics of interest. About $30 \%$ of the students claimed that they had limited time to study many different resources and needed to optimize their study activities. When the textbook reading is not directly tied to assessments, students often choose to study other resources they deem to be more beneficial.

\section{DISCUSSION}

The purpose of this study was to examine the factors that motivate students to use required textbooks, determine their preferred textbook format, and investigate how students learn and prepare to meet course requirements. The results show that a majority of students used online resources instead of assigned reading materials. When textbook reading is not directly tied to assessments, students often choose to study other resources they deem to be more beneficial. Most students indicated that they would read the text materials if reading materials are directly tied to tests, otherwise, they would opt for online resources on specific topics as needed. A good proportion of students claimed they spent far less time when using online resources to prepare for tests compared to reading the required textbook. Our results indicated $64 \%$ students spent less than one hour read their materials every week, and $26 \%$ students spent one to two hours on reading textbook. This, much like previous research (Burchfield \& Sappington, 2000; Clump, Bauer, \& Bradley, 2004; Clump \& Doll, 2007; Phillips \& Phillips, 2007), suggests students are increasingly reading less and less. There are also conflicting research results on whether textbook reading in university-level courses is correlated with improvements in student grades.

The results of this study and the conflicting results of previous research on the use and efficacy of textbooks appear to suggest that the textbook as a learning instrument needs to change to support "How People Learn (7 Implications for Learning in School, 2018)." Indeed research on textbook reading has demonstrated the importance of integrating supplemental resources into the classroom to enhance learning. Presently, the textbook in its various forms has limitations that make it less effective as a learning and instructional instrument. The information gleaned from these research initiatives must be used to develop resources and strategies that will promote a more effective use of the textbook.

Currently, there are two main development paths for textbooks: E-textbooks steered by the EPUB specification (EPUB 3 Overview, 2019) and Web Publications (Web Publications Use Cases and Requirements, 2019) being promoted by the W3C Publishing Working Group. The EPUB textbook cannot provide an integrated learning environment because it lacks full support for Scripting and tools to support various learning activities. Web Publications as alternative to EPUB publications, as envisaged, will be based on standard Open Web Platform 


\section{Issues in Information Systems}

Volume 20, Issue 4, pp. 35-44, 2019

(OWP) technologies. The new form of textbook that provides learning content as well as methods, processes, and tools that enhance learning is perhaps what is needed by today's learners.

\section{REFERENCES}

"7 Implications for Learning in School." National Academies of Sciences, Engineering, and Medicine. 2018. How People Learn II: Learners, Contexts, and Cultures. Washington, DC: The National Academies Press. doi: $10.17226 / 24783$.

Aagaard, L., \& Skidmore, R. (2004, November). Student study habits and the relationship to test scores in an undergraduate course. Paper presented at the annual meeting of the Midsouth Educational Research Association, Gatlinburg, TN.

Aagaard, L., \& Skidmore, R. (2009). College Student Use of Textbooks. Paper presented at the annual meeting of the Mid-South Educational Research Association Baton Rouge, LA, November 6, 2009

Aagaard, Lola \& W. Conner II, Timothy \& L. Skidmore, Ronald. (2014). College textbook reading assignments and class time activity. Journal of the Scholarship of Teaching and Learning. 14. 132.

10.14434/josotl.v14i3.5031.

Berry, T., L. Cook, N. Hill, \& K. Stevens. 2011. An Exploratory Analysis of Textbook Usage and Study Habits: Misperceptions and Barriers to Success. College Teaching, 59(1), 31-9.

Bharuthram, S. (2012). Making a case for the teaching of reading across the curriculum in higher education. South African Journal of Education, 32, 205-214.

Burchfield, C. M., \& Sappinton, J. (2000). Compliance with required reading assignments. Teaching of Psychology, $27,58-60$.

Clump, M. A., Bauer, H., \& Bradley, C. (2004). The extent to which psychology students read textbooks: A multiple class analysis of reading across psychology. Journal of Instructional Psychology, 31, 227-232. Retrieved October 16, 2009, from EBSCOhost Academic Search Premier database.

Cummings, K. C. S. U., French, T., \& Cooney, P. J. (2002, August). Student textbook use in introductory physics. In Physics Education Research Conference (pp. 7-8).

David Wiley (2017). The Evolving Economics of Educational Materials and Open Educational Resources: Toward Closer Alignment with the Core Values of Education, in Robert A. Reiser and John V. Dempsey, eds., Trends and Issues in Instructional Design and Technology, fourth ed., Pearson Education, 2017.

EPUB 3 Overview (2019). Final Community Group Report 10 May 2019.https://w3c.github.io/publ-epubrevision/epub32/spec/epub-overview.html

Fernald, P. S. (2004). The Monte Carlo quiz: Encouraging punctual completion and deep processing of assigned readings. College Teaching, 52(3), 95-99.

Fischer, L., Hilton, J., Robinson, J. T., \& Wiley, D. A. (2015). A Multi-Institutional Study of The Impact of Open Textbook Adoption On The Learning Outcomes Of Post-Secondary Students. Journal of Computing in Higher Education, 27(3), 159-172. 


\section{Issues in Information Systems}

Volume 20, Issue 4, pp. 35-44, 2019

French, M., Taverna, F., Neumann, M., Kushnir, L. P., Harlow, J., Harrison, D. \& Serbanescu, R. (2015). Textbook Use in the Sciences and Its Relation to Course Performance. College Teaching, 63, 171-177.

Hoeft, M. E. (2012). Why University Students Don't Read: What Professors Can Do to Increase Compliance. International Journal for the Scholarship of Teaching and Learning, 6(2), 1-18.

Huang, S., Capps, M., Blacklock, J., \& Garza, M. (2014). Reading habits of college students in the United States. Reading Psychology, 35(5), 437-467.

Lane, F., Hilton, J., Robinson, J. \& Wiley, D. (2015). A Multi-Institutional Study of the Impact of Open Textbook Adoption on the Learning Outcomes of Post-Secondary Students. Journal of Computing in Higher Education, 27(3), 159-172.

Marchant, G. J. (2002). Student Reading of Assigned Articles: Will This Be on the Test? Teaching of Psychology $29(1), 49-50$.

Mokhtari, K., Reichard, C. A., \& Gardner, A. (2009). The impact of internet and television use on the reading habits and practices of college students. Journal of Adolescent and Adult Literacy, 52(7), 609-619.

Podolefsky, N. \& Finkelstein, N. (2006). The Perceived Value of College Physics Textbooks: Students and Instructors May Not See Eye to Eye. The Physics Teacher, 44, 338-342. 10.1119/1.2336132.

Sappington, J., Kinsey, K., \& Munsayac, K. (2002). Two Studies of Reading Compliance among College Students. Teaching of Psychology, 29(4), 272-274. https://doi.org/10.1207/S15328023TOP2904_02

Sheorey, R., \& Mokhtari, K. (1994). The reading habits of developmental college students at different levels of reading proficiency. Reading Improvement, 31(3), 156.

Sikorski, J. F., Rich, K., Saville, B. K., Buskist, W., Drogan, O., \& Davis, S. F. (2002). Student use of introductory texts: Comparative survey findings from two universities. Teaching of Psychology, 29, 312-313. Retrieved October 16, 2009, from EBSCOhost Academic Search Premier database.

Starcher, K. \& Proffitt, D. (2011). Encouraging Students to Read: What Professors Are (and Aren't) Doing about It. International Journal of Teaching and Learning in Higher Education, 23(3), 396-407.

Wandersee, J. H. (1988). Ways students read texts. Journal of Science Teaching, 25, 69-84.

Web Publications Use Cases and Requirements. W3C Working Group Note 19 February 2019. https://www.w3.org/TR/2019/NOTE-pwp-ucr-20190219/ 


\section{Appendix A}

Survey questions on how much textbooks are used

1. What is your classification?

2. Is textbook required for this course?

3. Specify the type of textbook.
a. Hard copy
b. e-book
c. Hard copy but not required
d. e-book or free online materials but not required
e. Handouts by Instructor
f. Others-not fit in any categories above

4. Did you buy the textbook if it is not free?

5. How often did you use the textbook EVERY WEEK if there are textbooks assigned for this course?
a. Seldom use the book
b. 1-2 hours
c. 3-4 hours
d. More than 4 hours
e. Never used textbook
f. NA-no textbook

6. What is your major?

7. Do you use any online resources for this course?

8. Do your instructors assign homework questions directly from the course textbook (if textbook is required)?

9. If you have options to choose for the course, which one of the following formats you prefer?
a. Hard copy book
b. e-book
c. online resources compiled by instructor
d. Instructor hand-out
e. Others

10. Based on your preference on the textbook format, please give reasons why you prefer your choice? And list what are the most important features a "good textbook" should have, as well as the most important reasons why you DO NOT/ SELDOM read textbook, or list features you do not like. Please use bullet list. 